\title{
Mixed-Type Melasma Treated with Low Fluence Q-Switched Nd-YAG 1064 nm Laser: A Case Report
}

\author{
Aninda Fitri Nugrahani, Sinta Murlistyarini \\ Department of Dermatology and Venereology, DR. Saiful Anwar Hospital, Malang, East Java \\ Faculty of Medicine, Universitas Brawijaya, Malang, East Java
}

\section{ABSTRACT}

Background: Melasma is an acquired, chronic hypermelanosis condition. Melasma is more common in women of all races and occur especially on the face. The pathogenesis of melasma is very complex and the treatment is still a challenge. The purpose of this study was to report mixed-type melasma treated with low fluence Q-switched Nd-YAG $1064 \mathrm{~nm}$ laser.

Case Presentation: A case of melasma in 54 year old woman was reported. Dermatological examination showed presence of brownish macules and patches in the centro facial area with symmetrical distribution. Examination with wood lamp showed mixed type. Patients have received topical therapy but there were no improvement.

Results: The patient was then treated with low fluence Q-switched Nd-YAG $1064 \mathrm{~nm}$ laser for three sessions with an interval of 2 weeks. At 6 weeks of treatment the modified MASI (mMASI) value was reduced from 8.4 to 4.6 and the VAS value was increased from 2 to 8 .

Conclusion: The depth of the pigment determined the response to therapy. In the mixed type melasma the response for therapy is only partial. The low-fluence Q-switched Nd-YAG $1064 \mathrm{~nm}$ laser can penetrate deeper into the dermis and damage melanin in a short time.

Keywords: mixed typed melasma, low fluence, Q-switched Nd-YAG laser

\section{Correspondence:}

Aninda Fitri Nugrahani. Department of Dermatology and Venereology, DR. Saiful Anwar Hospital, Malang, East Java/ Faculty of Medicine, Universitas Brawijaya, Malang, East Java. Email: aninda16fitri@gmail.com

\section{Cite this as:}

Nugrahani AF, Murlistyarini S (2020). Mixed-Type Melasma Treated with Low Fluence Q-Switched NdYAG 1064 nm Laser: A Case Report. Indones J Med. 05(02): 95-101. https://doi.org/10.26911/theijmed.2020.05.02.01.

(c) (i) Indonesian Journal of Medicine is licensed under a Creative Commons

Attribution-NonCommercial-ShareAlike 4.o International License.

\section{BACKGROUND}

Melasma is an acquired, chronic hypermelanosis condition that can cause aesthetic disorders and decrease the patients' quality of life. Melasma is common in women of reproductive age of all races and is characterized by symmetrical, homogenous and irregular brown macules in areas exposed to sunlight, especially the face (Tamega et al, 2013). Epidemiological data in the Cosmetic Dermatology Clinic of Dermatology and Venereology Department in Dr. Cipto Mangunkusumo Hospital, Jakarta in 2011 showed the number of melasma patients was $18.1 \%$ of the total 3,763 visits, with a distribution of $98.4 \%$ was female patients and the remaining $1.6 \%$ was male (Melyawati et al, 2014).

The pathogenesis of melasma is still unclear, but the factors of genetic, hormonal, and ultraviolet (UV) radiation are thought to play a role. Other factors that are thought to contribute to the occurrence of melasma are the use of phototoxic drugs, anticonvulsant drugs, and the use of certain cosmetics (Moubasher et al, 2014). Various therapeutic modalities have been used to treat melasma, including bleaching agents, 
chemical peeling, and various laser therapy (Choi et al, 2015). Melasma often does not improve with chemical peeling therapy or topical therapies such as hydroquinone, retinoid, azelaic acid or kojic acid due to resistance to these agents and rapid recurrence in the formation of melasma lesions (Sim et al, 2015). Since 2006, the use of low-fluence 1064-nm Q-switched Neodymium: Yttrium-Aluminum-Garnet (QS NdYAG), a technique known as "laser toning", became popular for melasma therapy. Although said to be effective, this Nd-YAG QS laser can cause hypopigmentation in some patients(Kim et al, 2013)

In this case report a 54-year-old woman with mixed-type melasma will be treated with a 1064-nm low-fluence Qswitched Neodymium-Yttrium-AluminumGarnet laser.

\section{CASE PRESENTATION}

A 54-year-old woman came to the Dermatology and Venereology Clinic of Dr. Saiful Anwar Hospital Malang, with complaint of dark spots on his face. These spots have appeared since 1 year ago. Spots initially appear in the nose area, then spread to the right and left cheeks and forehead. The spots do not feel itchy, hot, or painful. Before the spots appear the patient denies the presence of acne or irritation in the area. One month before going to the hospital the patient visited his son who lived in Kalimantan and the patient felt his spots darken.

Patient is a housewife. Besides doing household activity, she also actively participating in the recitation around the house. The patient said that she had routinely used cream from a beauty clinic $>5$ years. About 4 months ago the patient changed her beauty clinic and got a morning and night cream. The creams are used for 2.5 months. The patient said there was no change in the spots. The past month, she has not used any treatment cream. Patients said she never wear sunscreen routinely every day.

The patient has 2 children. Between the first and the second child, she used implant contraceptive for 5 years. After the birth of the second child, she underwent tubectomy. The patient said that she had never taken hormonal drugs such as birth control pills or other drugs on a regular basis. The patient said that neither the patient's mother nor the patient's brother had the same complaints as the patient.

\section{RESULTS}

On physical examination the patient's blood pressure was obtained 120/80 mmHg, with a pulse of $68 \mathrm{x} / \mathrm{min}$, a respiratory rate of 20x / min, and a temperature of $36.7^{\circ} \mathrm{C}$. On dermatological examination on the face at centrofacial area, patches and macules of dark brown color with firm boundaries and irregular shapes are found. On examination with Wood's lamp, it was found that there were some spots with firm boundaries and other spots with unclear boundaries.

Figure 1 depicted dermatological examination. Figure 1 showed dark brown patches and macules with firm borders and irregular shapes at the centro facial part of the face.

Figure 2 depicted wood lamp examination. Figure 2 obtained some spots with firm boundaries and other spots with indefinite boundaries.

The patient was diagnosed with mixed-type melasma. Patients were then planned to get low-fluence laser therapy QSwitch Neodymium Yttrium Aluminum Garnet $1064 \mathrm{~nm}$ every 2 weeks. During the laser therapy period patients are required to wear wide-spectrum sunscreen with SPF 30 at least 2 times per day. Patients provided written informed consent to participate in the study. 


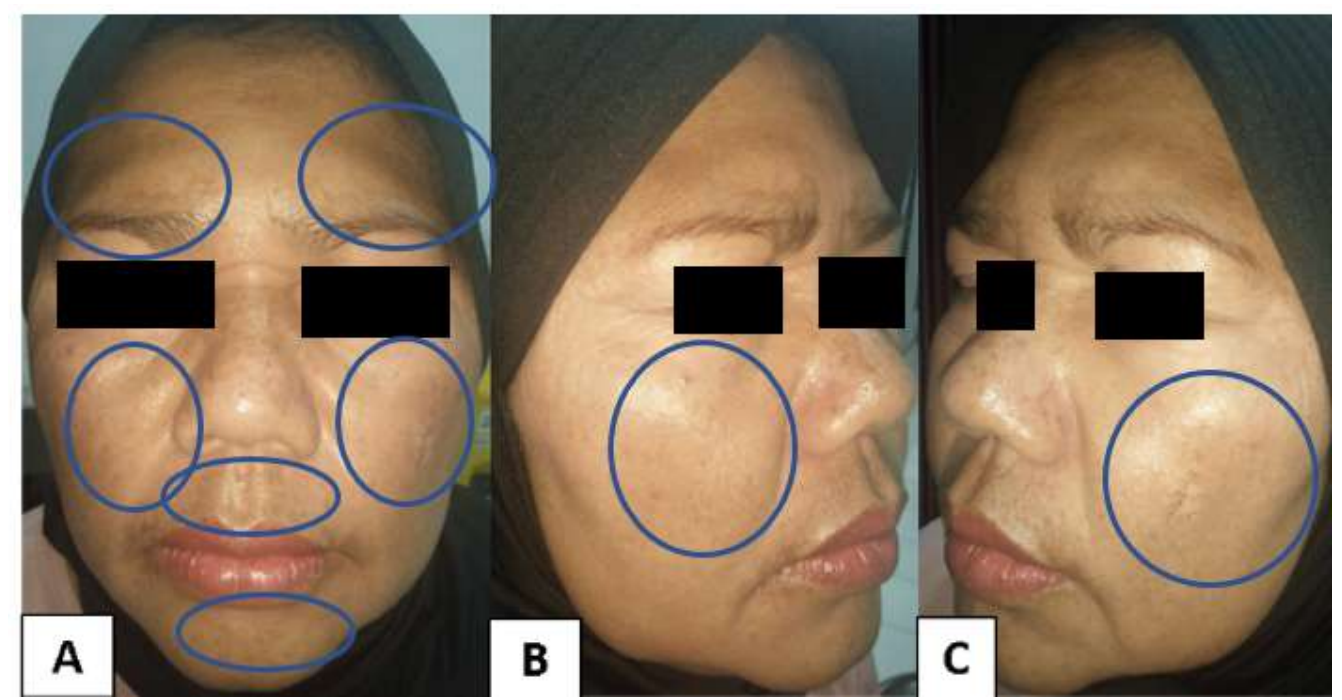

Figure 1 A, B, C. Dermatological examination.
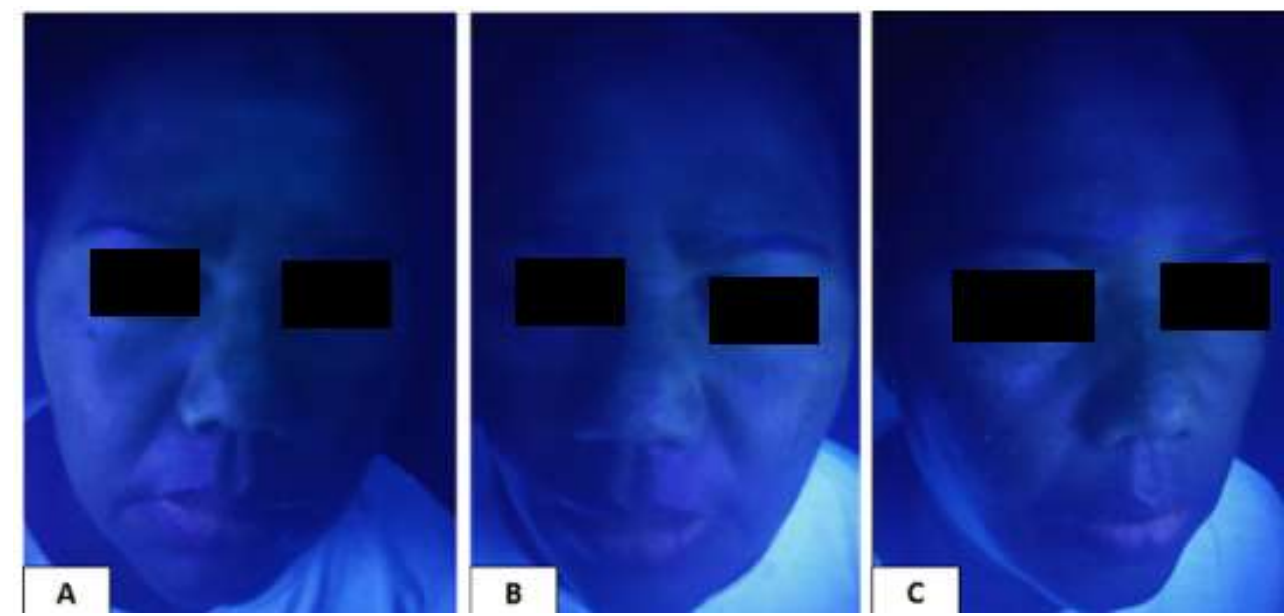

Figure 2 A, B, C. Wood lamp examination
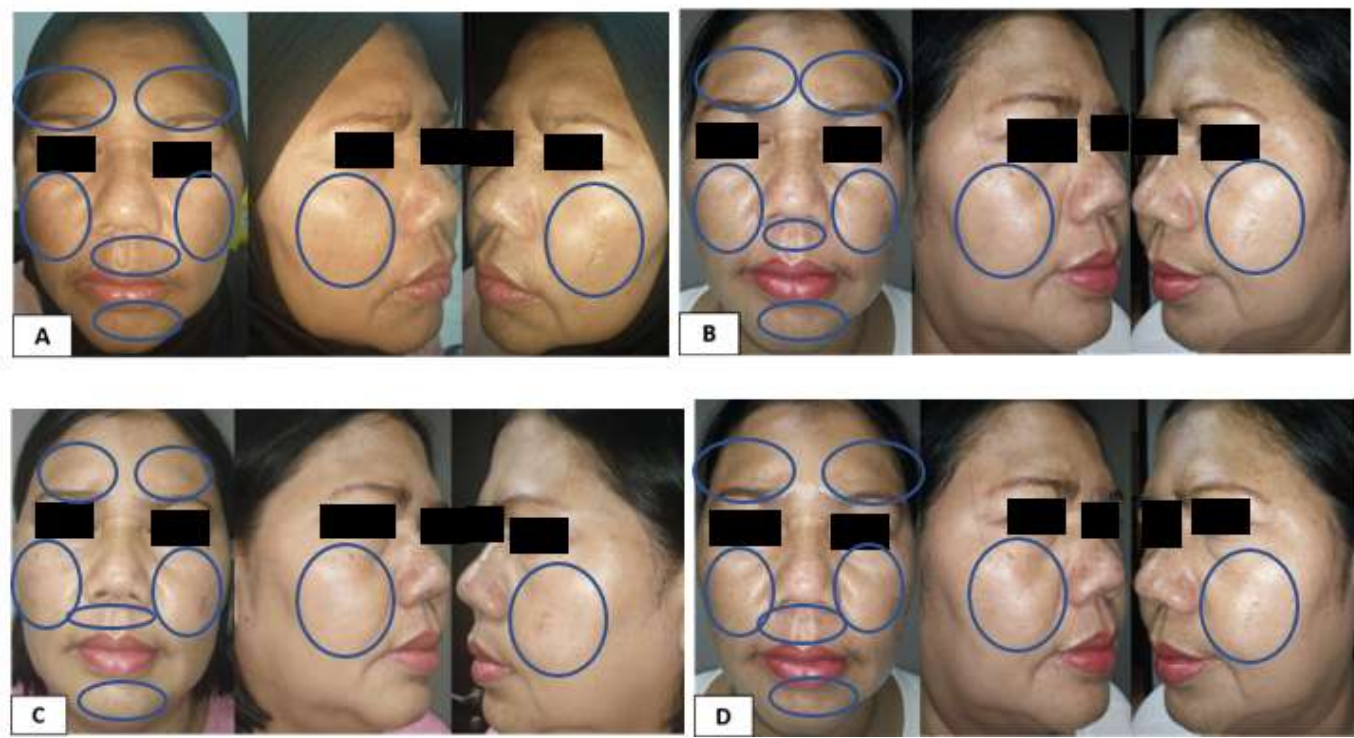

Figure 3. Follow up of therapy. A. $4^{\text {th }}$ week B. $2^{\text {nd }}$ week C. $4^{\text {th }}$ week D. $6^{\text {th }}$ week 
Nugrahani et al./ Low fluence Q-switched Nd-YAG $1064 \mathrm{~nm}$ laser for mixed-type melasma

Before laser therapy, the patient is given topical anesthesia with $2.5 \%$ lidocaine and 2.5\% prilocaine for 30-45 minutes. After that topical anesthesia was cleaned with sterile gauze moistened with $0.9 \% \mathrm{NaCl}$. Patients received QS: Nd-YAG laser therapy with a wavelength of $1064 \mathrm{~nm}$, spot size of
$8 \mathrm{~mm}$, fluence $2.0 \mathrm{~J} / \mathrm{cm} 2$, and 3 times fit the entire face. The end point of this therapy is the presence of erythema on the skin and warm palpable skin. After therapy, a cold compress with $0.9 \% \mathrm{NaCl}$ is applied to reduce the patient's burning sensation. Laser therapy is performed every 2 weeks.

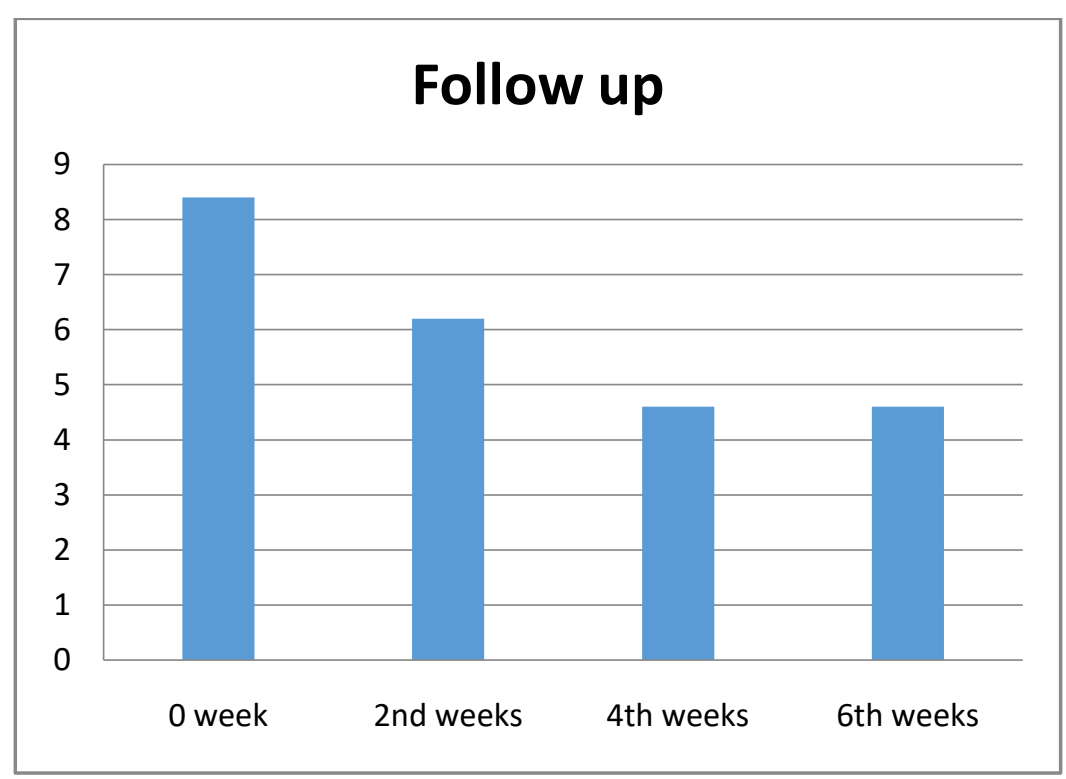

Figure 4. The improvement of mMASI value

At the time of initial examination, the modified MASI (mMASI) score was 8.4. Two weeks after the first laser, the mMASI score decreased by 2.2 , so the score on the second week became 6.2. In the fourth week the score dropped again to 4.6 and in the sixth week the mMASI score remained 4.6 (Figure 4).

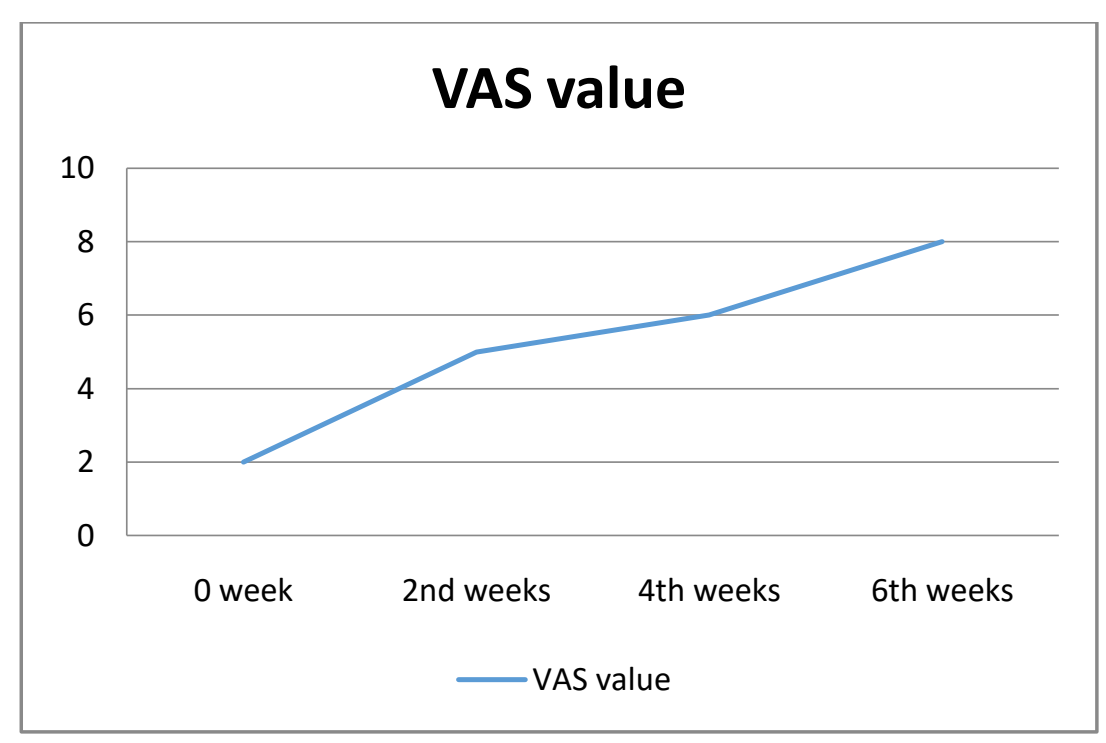

Figure 5. The improvement of VAS values 
Nugrahani et al./ Low fluence Q-switched Nd-YAG $1064 \mathrm{~nm}$ laser for mixed-type melasma

To evaluate patient satisfaction, Visual Analogue Scale (VAS) is used in the range $0-10$, where 0 is no improvement and 10 is a very satisfying improvement. Evaluation was carried out at weeks o, 2, 4, 6, and 8. VAS values obtained were 2, 5, 6, and 8 . There were no significant side effects in patients (Figure 5).

\section{DISCUSSION}

Melasma is a chronic condition of hypermelanosis obtained on the skin, which is characterized by brown macules with irregular shapes and symmetrically distributed in areas of the body exposed to sunlight, especially the face(Handel et al, 2014). This disorder occurs most commonly between the ages of 30 and 40 years. Family history affects the occurrence of melasma in people with Fitzpatrick skin types II and III, whereas in darker skin types family history has no effect. Melasma is more common in female with a ratio of 9: 1 compared to male. In Southeast Asia the prevalence in adult women reaches $40 \%$ and in adult men 20\% (Cestari et al, 2017).

Several studies have shown that there are increasing in both melanocytosis and melanogenesis in melasma patients. Some factors that can be triggers include sun exposure, use of oral contraceptives, thyroid disease, pregnancy, and medications (Sarkar et al, 2014). Study conducted by KrupaShankar et al in India shows that the most dominant trigger factor for melasma is sun exposure(KrupaShankar et al, 2014).

Facial melasma can be divided into 3 patterns based on the affected face area, namely centro facial pattern, malar pattern, and mandible pattern. In the centro facial pattern the affected area is the forehead, cheeks, upper lip, nose, and chin. Whereas in malar pattern the lesions are only found on the cheeks and nose, and in the pattern of the mandible the area involved is the ramus of the mandible(Rigopoulos et al, 2017). While based on the depth of the pigment, the type of melasma is divided into three, namely the dermal type, epidermal type, and mixed type. On Wood's lamp examination, dermal-type melasma is clearer and darker, while in the dermal type less fluorescence can be captured. The depth of the pigmentation also affects melasma therapy. In epidermal type, the response to therapy is better than the dermal type. And in mixed types, the response produced is only partial (Sarkar et al, 2014). In this case report found melasma in 54 years old woman. Patients never use sunscreen. Dermatological examination revealed brownish macules in the centro facial area and Wood's lamp examination showed mixed type.

The treatment of melasma consists of medical and non-medical therapy. In medical management can be given topical drugs, systemic drugs, and minimally and invasive treatment such as lasers and light and chemical peeling. Non-medical management can be topical such as skin care products, decorative cosmetics, or skin lightening cosmetics, and can also be systemic for example consumption of antioxidants (Wasitaadmaja et al, 2018).

Laser therapy in pigmented lesions is based on the theory of selective photothermolysis proposed by Anderson and Parrish. The theory states that when specific energy wavelengths are released in a shorter period of time than the thermal relaxation time (TRT) of the target chromophore, the energy will be retained in the target cell and cause less damage to the surrounding area (Arora et al, 2012). Laser quality-switched (Q-switched) produces high-intensity laser beams with very short pulse durations. The new variant of Q-switched laser is known as low fluence or Q-switched sub-termolytic therapy(Trivedi et al, 2017). Fluence used in 
Nugrahani et al./ Low fluence Q-switched Nd-YAG $1064 \mathrm{~nm}$ laser for mixed-type melasma

sub-termolytic laser therapy is $<5 \mathrm{~J} / \mathrm{cm}^{2}$ (Wattanakrai et al, 2010). Low fluence therapy using a wavelength of $1064 \mathrm{~nm}$ (QS: NdYAG) can penetrate deeper into the dermis and a little affects the epidermis (Trivedi et al, 2017).

The selection of the right beam diameter or spot size is important in the treatment of pigmented lesions. Large spot sizes are safer for the epidermis and are preferred for dark skin types (Small et al, 2016). Spot sizes between 7-10 mm produce maximum penetration to the dermis tissue. Deeper penetration will not be achieved if the spot size is above $10-12 \mathrm{~mm}$ (Nouri, 2014).

Patients were given a $1064 \mathrm{~nm}$ Qswitched Nd-YAG laser therapy with $2 \mathrm{~J} /$ $\mathrm{cm}^{2}$ fluence, $8 \mathrm{~mm}$ spot size, and 3 passes. 3 laser sessions with a 2-week interval showed improvement in the lesion marked by a decrease in the mMASI score and an increase in the VAS score. There were no laser side effects in patients, either hyperpigmentation, hypopigmentation, or the presence of scars.

\section{AUTHOR CONTRIBUTION}

Both authors developed the concept for this manuscript and edited multiple drafts of the manuscript.

\section{FUNDING AND SPONSORSHIP}

There was no sponsorship in this study.

\section{CONFLICT OF INTEREST}

There is no conflict of interest in this study.

\section{ACKNOWLEDGEMENT}

The authors were fully responsible for all content and editorial decisions and received no financial support or other form of compensation related to the development of this manuscript.

\section{REFERENCE}

Arora P, Sarkar R, Garg VK, Arya L (2012). Lasers for treatment of melasma and post-inflammatory hyperpigmentation. Journal of cutaneous and aesthetic surgery, 5(2): 93. doi: 10.4103/o974-2077.99436

Cestari T, Peruzzo J, Giongo N (2017). Definition, incidence, and etiology of melasma in brown skin. In Melasma and Vitiligo in Brown Skin. Springer, New Delhi.doi: 10.1007/978-81-3223664-1_3

Choi CP, Yim SM, Seo SH, Ahn HH, Kye YC, Choi JE (2015). Retrospective analysis of melasma treatment using a dual mode of low-fluence Q-switched and long-pulse Nd: YAG laser vs. lowfluence Q-switched Nd: YAG laser mono-therapy. Journal of Cosmetic and Laser Therapy, 17(1): 2-8. doi: 10.3109/14764172.2014.957217

Handel AC, Miot LDB, Miot HA (2014). Melasma: a clinical and epidemiological review. Anais brasileiros de dermatologia, 89(5): 771-782. doi: 10.159o/abd1806-4841.20143063

Kim JE, Chang SE, Yeo UC, Haw S, Kim IH (2013). Histopathological study of the treatment of melasma lesions using a low-fluence Q-switched 1064-nm neodymium: yttrium-aluminium-garnet laser. Clinical and Experimental Dermatology: Clinical dermatology, 38 (2): 167-171. doi: 10.1111/j.1365-2230.2012.04473.x

KrupaShankar DSR, Somani VK, Kohli M, Sharad J, Ganjoo A, Kandhari S, Kadhe G (2014). A cross-sectional, multicentric clinico-epidemiological study of melasma in India. Dermatol Ther (Heidelb), 4(1): 71-81.doi: 10.1007/s13555-014-0046-1 
Nugrahani et al./ Low fluence Q-switched Nd-YAG 1064 nm laser for mixed-type melasma

Melyawati SS, Bernadette I, Legiawati L (2014). Perkembangan terbaru etiopatogenesis melasma. Media Dermato-Venereologica Indonesiana, 41(3): 133-138. Retrieved from http://www.perdoski.or.id/doc/mdvi/fulltex t/33/220/13_Tinjauan_Pustaka.pdf.

Moubasher AE, Youssef EM, Abou-Taleb DA (2014). Q-switched Nd: YAG laser versus trichloroacetic acid peeling in the treatment of melasma among Egyptian patients. Dermatologic Surgery, 40(8): 874-882.doi: 10.1097/DSS.0000000000000065

Nouri K (2014). Handbook of Laser in Dermatology. London: Springer.

Rigopoulos D, Katoulis AC (2017). Hyperpigmentation. CRC Press. Retrieved from https://www.crcpress.com/Hyperpigmentation/Rigopoulos-Katoulis/p/book/9781498740173

Sarkar R, Arora P, Garg VK, Sonthalia S, Gokhale N (2014). Melasma update. Indian dermatology online journal, 5(4): 426.doi: 10.4103/2229-5178.142484

Sim JH, Park YL, Lee JS, Lee SY, Choi WB, Kim HJ, Lee JH (2014). Treatment of melasma by low-fluence $1064 \mathrm{~nm} \mathrm{Q-}$ switched Nd: YAG laser. Journal of Dermatological Treatment, 25(3):
212-217. doi: 10.3109/09546634.2012.735639

Small R, Hoang DA (2016). Practical Guide to Laser Procedures. Philadelphia: Walters Kluwer

Tamega ADA, Miot LDB,Bonfietti C,Gige TC, Marques MEA,Miot HA (2013). Clinical patterns and epidemiological characteristics of facial melasma in Brazilian women. Journal of the European Academy of Dermatology and Venereology, 27(2): 151-156. Retrieved

fromhttps://doi.org/10.1111/j.14683083.2011.04430.x

Trivedi MK, Yang FC, Cho BK (2017). A review of laser and light therapy in melasma. International journal of women's dermatology, 3(1): 11-20. doi: 10.1016/j.ijwd.2017.01.004

Wasitaadmaja SM,Norawati L (2018). Pedoman Diagnosis dan Tata Laksana Melasma di Indonesia. Jakarta: Badan Penerbit FKUI

Wattanakrai P, Mornchan R, Eimpunth S (2010). Low-fluence Q-switched neodymium-doped yttrium aluminium garnet $(1.064 \mathrm{~nm})$ laser for the treatment of facial melasma in Asians. Dermatologic surgery, 36(1): 76-87. doi: $10.1111 /$ j.1524-4725.2009.01383.x. 